\title{
Risk Assessment Research of Enterprise BI Project Implementation Based on Fuzzy Comprehensive Assessment
}

\author{
XiaoLong MA \\ School of Information Management and Engineering, Shanghai University of Finance and Economics, \\ Shanghai 200433, China \\ Huzhou Teachers College ,Huzhou City, Zhejiang Province,313000 China
}

LanJuan LIU ${ }^{1}$

New Institute, Gouda, Netherlands

\begin{abstract}
Business Intelligence(BI) systems can help enterprise to make intelligent decision, but in an increasingly complex business environment, the implementation of BI like ERP system is facing a huge problem, pressure and high risk. In response to the above features, the paper proposes a fuzzy comprehensive assessment method of a BI project, analyses the risk factors associated with the BI project implementation, carries out the optimal discrimination, obtains the main factors leading to the risk and at the same time provides the scientific basis for risk avoidance of BI implementation, illustrated by the case of the Shanghai New Media Company A.
\end{abstract}

KEYWORD: Fuzzy Comprehensive Assessment; BI; risk assessment

Business intelligence (BI) system is a data intelligence decision-making system, utilizing artificial intelligence technology to handle and analyze enterprises, which is used to help business activities carry out rapid reaction, and accelerate obtaining speed of knowledge so as to increase commercial profits, and to meet requirements on time and accuracy of information knowledge from management level and decision-making level [1][2]. Various businesses of company A belonging to new medium operation type are under high-speed development stage, forming a core competitive advantage with radio and television characteristics. Among these core advantages, mass data possessed by company $\mathrm{A}$ is no doubt the condition and basis for sustainable development of the company, so how to utilize such data in an effective and creative way, does not only relate to smooth expansion of the company's business, but relates to the realization of company A's role of new media operator, so it is imperative for the company to realize business intelligence system. However, for the new media industry of company A, there're external policies and market risks, as well as internal management and execution risks, so if preparation before test is not sufficient, it may cause more problems and higher risks during the implementation of BI project. Therefore it is required to adopt scientific methods, distinguish risks and carry out effective control on risks.

\section{RESEARCH SITUATION OVERVIEW}

Via retrieving representative journals, conferences, dissertation databases such as CNKI, Wanfang and VIP etc., research on business intelligence system in recent years mainly focuses on the following aspects:

(1) Technological and structural research on business intelligence. Research on this field mainly includes data warehouse, ETL, OLAP and data digging technological fields, which focuses on how to improve inquiry efficiency of business intelligence system, and to construct systematic structure of business intelligence.

(2) Implementation research of business intelligence in different industries. Research in this field mainly focuses on analysis, design and implementation process of business intelligence system in different industries such as telecommunication, finance and medical industry etc.

However, research on implementation risks of business intelligence is very rare, and the only research stays on qualitative research level, i.e. in the dissertation of written by Xie Gang from Beijing

\footnotetext{
1 *Author introduction: Ma Xiaolong (1976-), male, Baoji, Shanxi, Ph.D. student, tutorial, engaged in information management study. E-mail: 1xm2007@ sohu.com 13867279869

Liu Lanjuan (1960-), female, Shanghai, Professor, Ph.D. supervisor.
} 
Postal University, discussion on risky factors and evasion measures is also carried out combining specific case qualitatively. However, there's no findings combining quantitative and qualitative methods. Therefore, research is carried out in this dissertation about this, taking the implementation of BI system in company A - a new media industry company in Shanghai as an example, to discuss the disturbing fuzzy comprehensive assessment adopting a quantitative and qualitative combination, and carry out research on changes in various risky factors, so as to provide evidence for company A to take corresponding risk control measures, and to further enrich research in the field of business intelligence system.

\section{RISK INDEX CONSTRUCTION OF COMPANY A'S IMPLEMENTING BI PROJECT}

Via interviewing and questionnaire survey of the writer, it is found that company A is a leading IPTV new media business operator and provider in China, which mainly engages in business operation of IPTV, mobile TV, network TV, internet TV and mobile internet, with industrial particularity. Viewing from the implementation of BI project, risks are mainly classified into four aspects[3][4].

\subsection{External Risks}

External risks faced by company A mainly include policy risk, market risk, industrial risk, laws and regulations. At present, future policy on internet TV operation permit of the State Administration of
Radio Film and Television of China is not that clear, so several existing companies with operation license of the industry have not dominated the market, causing extremely fierce competition in the industry.

\subsection{Title, author and affiliation frame}

Technology risks mainly include five major factors which are namely fundamental data quality, data integration difficulty, existing system software and hardware compatibility, initial requirements clear degree and providers' serving ability. The most valuable significance of BI lies in tendency prediction and auxiliary decision, so detailed data is the base for a successful BI project, more basic data which is more specific and accurate could enable BI to bring more accurate prediction for the enterprise.

\subsection{Management Risks}

Management risks mainly contain four major factors which are namely support degree of management level, rationality of business process and organization structure, stability degree of project team, employee acceptance and resistance degree among employees. The implementation of BI project needs cooperation and support from all departments of company A, especially, for particularity of company A's industry, the existing organization structure is not that reasonable, and business process penetrating various departments is not that smooth, so it is required to carry out organization structure adjustment and business process optimization during the implementation of BI project, so the support from the head is necessary for the implementation of BI project.

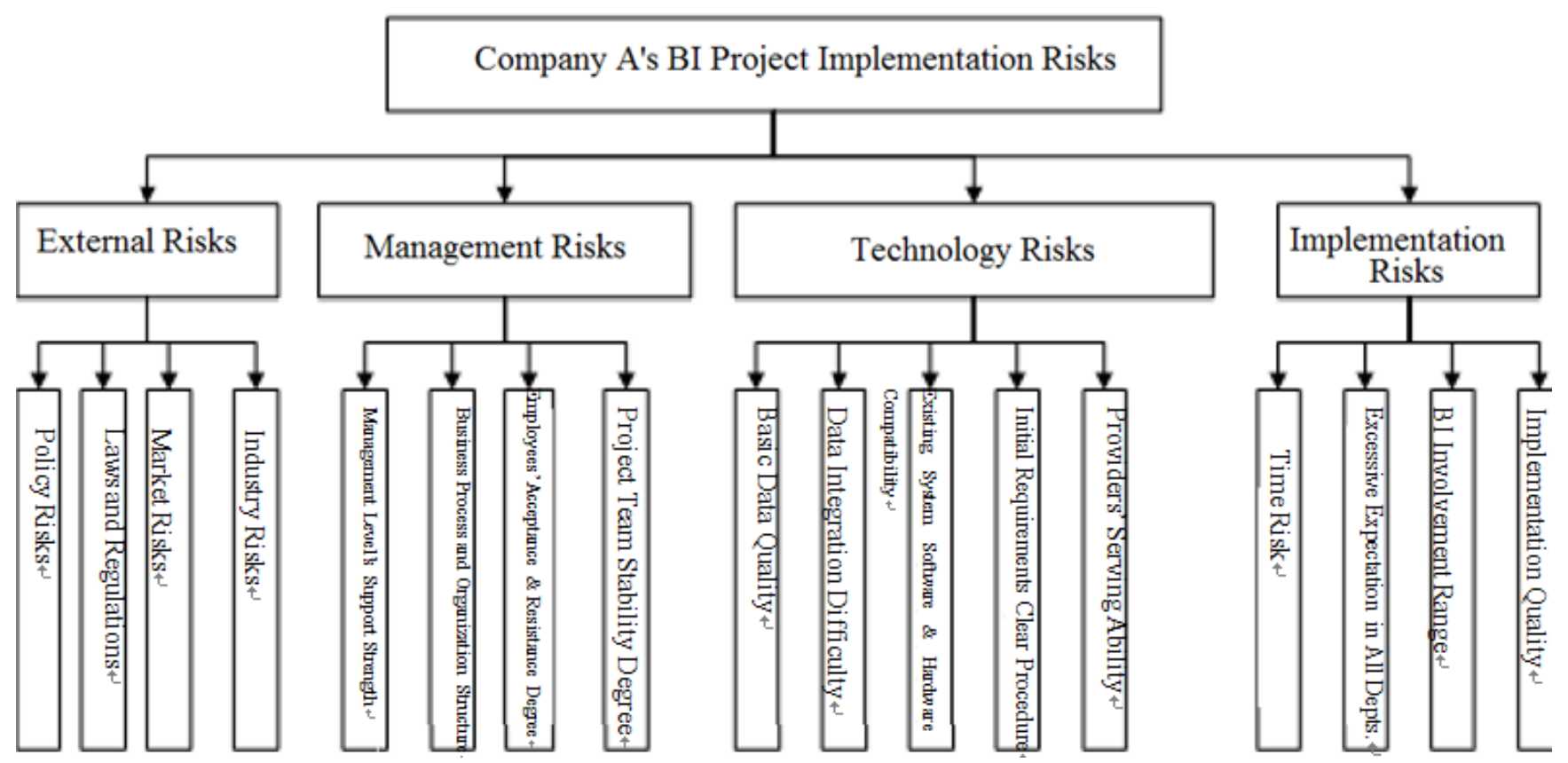

Figure 1 Hierarchy Structural Diagram for BI Implementation Risks Assessment Index of Company A 


\subsection{Implementation Risks}

Risks during implementation include four major risks which are namely time risk, excessive expectation in all departments, BI involvement scope as well as implementation quality. Time risk mainly reflects in the schedule control of BI implementation, and it is required to avoid falling into the "black hole" of implementation.

\subsection{BI Risk Index System Construction}

Based on the above analysis on risk factors, a risk assessment index system hierarchy structural diagram is established for company A in Shanghai, as shown in Figure 1.

\section{IMPROVEMENT OF FUZZY COMPREHENSIVE ASSESSMENT}

Some scholar carries out improvement on fuzzy Comprehensive Assessment - the disturbing fuzzy Comprehensive Assessment. Set $\mathrm{U}$ as the discourse domain, for any $\mu \subset U$, specifies a region $\left[U_{A}(\mu)-\varepsilon_{A}, U_{A}(\mu)+\varepsilon_{A}\right]$, in which $U_{A} \pm \varepsilon_{A} \subset[0,1]$ is a curve closing to $U_{A}(\mu)$. So A is defined that $\mathrm{A}$ as a disturbing fuzzy subset on the given discourse domain $U$. Mapping $\mathrm{U} \rightarrow[[0,1],[0,1]], \mu \rightarrow\left[U_{A}(\mu)-\varepsilon_{A}, U_{A}(\mu)+\varepsilon_{A}\right]$ is called a disturbing membership region function of A, hereinafter referred to as membership region[7][8].

\section{REALIZATION OF DISTRIBUTING FUZZY COMPREHENSIVE ASSESSMENT ON BI PROJECT IMPLEMENTATION RISKS OF A}

\subsection{Establish an Evaluation Factor Set}

Evaluation factor set refers to a set of various impacting factors involved by evaluating objects. Based on risk factors of company A's implementing BI project in the above, company A's evaluation factor set table is established, as shown in Table 1:

Level 1 risk factor set of company A could be achieved from Table 1: $\mathrm{U}=\left(\mathrm{U}_{1}, \mathrm{U}_{2}, \mathrm{U}_{3}, \mathrm{U}_{4}\right)$, in which each level 1 factor is composed of one level 2 factor set: $U i=\left(U_{i 1}, U_{i 2}, U_{i 3}, U_{i j}\right)$, in which $i$ is the sequential number of level 1 factor, while $j$ is the sequential number of level 2 factor.
Table 1 Company A’s BI Project Risk Assessment Factor Set Table

\begin{tabular}{|c|c|}
\hline Level 1 Index & Level 2 Index \\
\hline \multirow{4}{*}{ External $\mathrm{U}_{1}$} & Policy Risk $\mathrm{U}_{11}$ \\
\hline & Market Risk $\mathrm{U}_{12}$ \\
\hline & Industry Risk $\mathrm{U}_{13}$ \\
\hline & Laws and Regulations Risk $\mathrm{U}_{14}$ \\
\hline \multirow{4}{*}{$\begin{array}{l}\text { Management } \\
\mathrm{U}_{2}\end{array}$} & $\begin{array}{c}\text { Support Strength from Management } \\
\text { Level } U_{21}\end{array}$ \\
\hline & $\begin{array}{l}\text { Rationality of Business Process and } \\
\text { Organization Structure } \mathrm{U}_{22}\end{array}$ \\
\hline & Project Team Stability Degree $\mathrm{U}_{23}$ \\
\hline & $\begin{array}{l}\text { Acceptance and Resistance Degree } \\
\text { among Employees } U_{24}\end{array}$ \\
\hline \multirow{5}{*}{ Technology $\mathrm{U}_{3}$} & Basic Data Quality $\mathrm{U}_{31}$ \\
\hline & Data Integration Difficulty $\mathrm{U}_{32}$ \\
\hline & $\begin{array}{c}\text { Existing System Software and } \\
\text { Hardware Compatibility } \mathrm{U}_{33}\end{array}$ \\
\hline & Initial Requirements Clear Degree $\mathrm{U}_{34}$ \\
\hline & Providers' Serving Ability $\mathrm{U}_{35}$ \\
\hline \multirow{4}{*}{$\begin{array}{l}\text { Implementation } \\
\mathrm{U}_{4}\end{array}$} & Time Risk $\mathrm{U}_{41}$ \\
\hline & $\begin{array}{l}\text { Excessive Expectation in All } \\
\text { Departments } \mathrm{U}_{42}\end{array}$ \\
\hline & BI Involvement Range $\mathrm{U}_{43}$ \\
\hline & Implementation Quality $\mathrm{U}_{44}$ \\
\hline
\end{tabular}

\subsection{Determination on BI Project Implementation Risk Assessment Set}

Evaluation set is a kind of language description on evaluation indexes on all levels, which is a set of comments made by the reviewer on all indexes. In this dissertation, comments are classified into five levels. Detailed evaluation levels are as follows:

$\mathrm{V}=(\mathrm{v} 1, \mathrm{v} 2, \mathrm{v} 3, \mathrm{v} 4, \mathrm{v} 5)=\{$ High, Higher, Medium, Lower, Low

\subsection{Determination on Weight Set of BI Project Implementation Risks}

Determination on weight of various risk factors is the key cycle during the recognition on enterprise's BI project implementation risks, while different weight of various factors reflects the difference in importance in factors. In order to determine the weight of various indexes in a scientific manner, questionnaires are distributed to experienced BI experts, so that they could carry out importance evaluation on $\mathrm{BI}$ implementation factors of company $A$, and then carry out integration on statistical results, so as to obtain a membership region, as shown in Table 2. Set level 1 weight set $A=\left(\left[a_{1}\right.\right.$, $\left.\left.a_{1}\right],\left[a_{2}, a_{2}\right], \ldots \ldots,\left[a_{n}, n^{\prime}\right]\right)$, level 2 index $A_{i}=\left(\left[a_{i 1}\right.\right.$, $\left.\left.a_{i 1}\right],\left[a_{i 2}, a_{i 2}\right], \ldots . .,\left[a_{i m}, a_{i m}\right]\right)$. 
Table 2 Weight Table for BI Project Risks of Company A

\begin{tabular}{|c|c|c|c|}
\hline $\begin{array}{l}\text { Level } 1 \\
\text { Index }\end{array}$ & $\begin{array}{r}\text { Weight } \\
\text { Coefficient }\end{array}$ & Level 2 Index & $\begin{array}{r}\text { Weight } \\
\text { Coefficient }\end{array}$ \\
\hline \multirow{4}{*}{$\begin{array}{l}\text { External } \\
\text { Risk } U_{1}\end{array}$} & \multirow{4}{*}[0.18,0.24]{} & Policy Risk $U_{11}$ & {$[0.35,0.45]$} \\
\hline & & Market Risk $\mathrm{U}_{12}$ & {$[0.10,0.15]$} \\
\hline & & Industry Risk $\mathrm{U}_{13}$ & {$[0.25,0.35]$} \\
\hline & & Laws and Regulations Risk $\mathrm{U}_{14}$ & {$[0.05,0.12]$} \\
\hline \multirow{4}{*}{$\begin{array}{l}\text { Management } \\
\text { Risk } U_{2}\end{array}$} & \multirow{4}{*}[0.30,0.36]{} & Management Level's Support Strength $\mathrm{U}_{21}$ & {$[0.20,0.30]$} \\
\hline & & Rationality of Business Process and Organization Structure $\mathrm{U}_{22}$ & {$[0.38,0.48]$} \\
\hline & & Project Team Stability Degree $\mathrm{U}_{23}$ & {$[0.25,0.30]$} \\
\hline & & Acceptance and Resistance Degree among Employees $\mathrm{U}_{24}$ & {$[0.12,0.20]$} \\
\hline \multirow{5}{*}{$\begin{array}{l}\text { Technology } \\
\text { Risk } U_{3}\end{array}$} & \multirow{5}{*}[0.22,0.28]{} & Basic Data Quality $\mathrm{U}_{31}$ & {$[0.25,0.30]$} \\
\hline & & Data Integration Difficulty $\mathrm{U}_{32}$ & {$[0.05,0.12]$} \\
\hline & & Existing System Software and Hardware Compatibility $\mathrm{U}_{33}$ & {$[0.35,0.45]$} \\
\hline & & Initial Requirements Clear Degree $U_{34}$ & {$[0.18,0.25]$} \\
\hline & & Providers' Serving Ability $\mathrm{U}_{35}$ & {$[0.08,0.15]$} \\
\hline \multirow{4}{*}{$\begin{array}{l}\text { Implementati } \\
\text { on Risk } \mathrm{U}_{4}\end{array}$} & \multirow{4}{*}[0.11,0.18]{} & Time Risk $\mathrm{U}_{41}$ & {$[0.15,0.20]$} \\
\hline & & Excessive High Expectation in All Departments $\mathrm{U}_{42}$ & {$[0.25,0.30]$} \\
\hline & & BI Involvement Range $\mathrm{U}_{43}$ & {$[0.30,0.35]$} \\
\hline & & Implementation Quality $\mathrm{U}_{44}$ & {$[0.10,0.15]$} \\
\hline
\end{tabular}

\subsection{Determining Enterprise BI Project's Level Membership Degree, and Establishing Disturbing Fuzzy Matrix}

According to impacting degree of various risk factors on company A's BI project implementation, a team composed of 10 experts which are namely professionals from high schools, PHD researchers of the company, BI personnel from technology center, third party consultancy companies and third party technology developing companies is established, and these experts will score and summarize respectively, to form a summary table for company A's BI project implementation risk factor levels, as shown in Table 3.

Judgment matrix $\mathrm{R}_{\mathrm{ij}}$ for fuzzy relationship of Company A's BI project implementation risks is achieved from Table 3. i.e. external risk $\mathrm{R}_{11}$

$$
\begin{aligned}
& \mathrm{R}_{11=} \\
& \mid \begin{array}{lllll|}
{[0.40,0.50]} & {[0.30,0.35]} & {[0.10,0.18]} & {[0.05,0.10]} & {[0.01,0.05]} \\
{[0.05,0.10]} & {[0.12 .0 .18]} & {[0.45,0.55]} & {[0.18,0.22]} & {[0.08,0.12]} \\
{[0.01,0.05]} & {[0.40,0.50]} & {[0.30,0.38]} & {[0.10,0.20]} & {[0.050 .10]} \\
{[0.05,0.10]} & {[0.25,0.30]} & {[0.50,0.60]} & {[0.01,0.05]} & {[0.00,0.00]}
\end{array}
\end{aligned}
$$

\subsection{Determination on Disturbing Fuzzy Comprehensive Assessment, Using Disturbing Fuzzy Comprehensive Assessment Method}

According to the principle of disturbing fuzzy Comprehensive Assessment, formula $B_{i}=A_{i} \circ R_{i}$ is used to carry out level 1 disturbing fuzzy
Comprehensive Assessment, which is to integrate single-factor judgment matrix $R_{i}$ and its weight vector $A_{i}$ into a vector operation $\mathrm{M}(\otimes, \oplus)$. The obtained result is the evaluation for $U_{i} . B_{1}$ is calculated as follows:

$$
\begin{aligned}
& \mathrm{B}_{1}=\mathrm{A}_{1} \circ \mathrm{R}_{1}=\left.[0.35,0.45][0.10,0.15][0.25,0.35] \quad[0.05,0.12]\right|^{\circ} \\
& {\left[\begin{array}{llll}
{[0.40,0.50]} & {[0.30,0.35]} & {[0.10,0.18]} & {[0.05,0.10]} \\
{[0.01,0.05]}
\end{array}\right.} \\
& {\left[\begin{array}{llllll}
{[0.05,0.10]} & {[0.12,018]} & {[0.45,0.55]} & {[0.18,0.22]} & {[0.08,0.12]}
\end{array}\right.} \\
& {[0.01,0.05] \quad[0.40,0.50] \quad[0.30,0.38] \quad[0.10,0.20] \quad[0.05,0.10]} \\
& {\left[\begin{array}{llllll}
{[0.05,0.10]} & {[0.25,0.30]} & {[0.50,0.60]} & {[0.01,0.05]} & {[0.00,0.00]}
\end{array}\right.} \\
& =([0.35,0.40],[0.30,0.35],[0.25,0.30] \text {, } \\
& [0.15,0.20],[0.08,0.10])
\end{aligned}
$$

In the same way, we could know: $\mathrm{B}_{2}, \mathrm{~B}_{3}$ and $\mathrm{B}_{4}$.

Then according to the result from level 1 disturbing fuzzy Comprehensive Assessment to construct single-factor judgment matrix $\mathrm{R}$ for level 2 disturbing fuzzy comprehensive judgment.

$$
\begin{aligned}
& \mathrm{R}= \\
& \left|\begin{array}{lllll}
{[0.35,0.40]} & {[0.30,0.35]} & {[0.25,0.30]} & {[0.15,0.20]} & {[0.08,0.10} \\
{[0.38,0.40]} & {[0.30,0.35]} & {[0.24,0.25]} & {[0.15,0.22]} & {[0.15,0.18} \\
{[0.35,0.40]} & {[0.32,0.35]} & {[0.15,0.20]} & {[0.12,0.15]} & {[0.05,0.08} \\
{[0.30,0.35]} & {[0.28,0.30]} & {[0.18,0.20]} & {[0.15,0.20]} & {[0.05,0.10}
\end{array}\right|
\end{aligned}
$$

So $\mathrm{B}=\mathrm{A} \circ \mathrm{R}=$

$$
\text { ([0.30, 0.36],[0.30, 0.35],[0.24,0.25],[0.18,0.22],[0.15,0.18]) }
$$

Then equalize each region of vector $B$, we could obtain: $=(0.33,0.325,0.245,0.2,0.165)$. 
Table 3 Company A's BI Project Risks Comprehensive Assessment

\begin{tabular}{|c|c|c|c|c|c|c|}
\hline \multirow{2}{*}{$\begin{array}{l}\text { Level } 1 \\
\text { Index }\end{array}$} & \multirow{2}{*}{ Level 2 Index } & \multicolumn{5}{|c|}{ Risk Levels } \\
\hline & & High & Higher & Medium & Lower & Low \\
\hline \multirow{4}{*}{$\begin{array}{l}\text { External } \\
\text { Risk }\end{array}$} & Policy Risk & {$[0.40,0,50]$} & {$[0.30,0.35]$} & {$[0.10,0.18]$} & {$[0.05,0.10]$} & {$[0.01,0.05]$} \\
\hline & Market Risk & {$[0.05,0.10]$} & {$[0.12,0.18]$} & {$[0.45,0.55]$} & {$[0.18,0.22]$} & {$[0.08,0.12]$} \\
\hline & Industry Risk & {$[0.01,0.05]$} & {$[0.40,0.50]$} & {$[0.30,0.38]$} & {$[0.10,0.20]$} & {$[0.05,0.10]$} \\
\hline & $\begin{array}{c}\text { Laws and } \\
\text { Regulation Risk }\end{array}$ & {$[0.05,0.10]$} & {$[0.25,0.30]$} & {$[0.50,0.60]$} & {$[0.01,0.05]$} & {$[0.00,0.00]$} \\
\hline \multirow{4}{*}{$\begin{array}{l}\text { Management } \\
\text { Risk }\end{array}$} & $\begin{array}{c}\text { Management } \\
\text { Level Support } \\
\text { Strength } \\
\end{array}$ & {$[0.10,0,20]$} & {$[0.35,0.40]$} & {$[0.25,0.30]$} & {$[0.02,0.10]$} & {$[0.02,0.10]$} \\
\hline & $\begin{array}{l}\text { Rationality of } \\
\text { Business Process } \\
\text { and Organization } \\
\text { Structure } \\
\end{array}$ & {$[0.40,0.50]$} & {$[0.30,0.35]$} & {$[0.14,0,20]$} & {$[0.05,0.10]$} & {$[0.01,0.05]$} \\
\hline & $\begin{array}{c}\text { Project Team } \\
\text { Stability Degree }\end{array}$ & {$[0.30,0.35]$} & {$[0.40,0.50]$} & {$[0.15,0.22]$} & {$[0.01,0.05]$} & {$[0.01,0.05]$} \\
\hline & $\begin{array}{l}\text { Acceptance } \\
\text { and Resistance } \\
\text { Degree among } \\
\text { Employees }\end{array}$ & {$[0.10,0.15]$} & {$[0.20,025]$} & {$[0.40,0.50]$} & {$[0.05,0.10]$} & {$[0.10,0.15]$} \\
\hline \multirow{5}{*}{$\begin{array}{l}\text { Technology } \\
\text { Risk }\end{array}$} & $\begin{array}{l}\text { Basic Data } \\
\text { Quality }\end{array}$ & {$[0.30,0.35]$} & {$[0.35,0.40]$} & {$[0.15,0.20]$} & {$[0.10,0.15]$} & {$[0.01,0.05]$} \\
\hline & $\begin{array}{c}\text { Data } \\
\text { Integration } \\
\text { Difficulty } \\
\end{array}$ & {$[0.10,0.15]$} & {$[0.15,0.20]$} & {$[0.20,0.30]$} & {$[0.32,0.40]$} & {$[0.05,0.10]$} \\
\hline & $\begin{array}{c}\text { Existing } \\
\text { System Software } \\
\text { and Hardware } \\
\text { Compatibility }\end{array}$ & {$[0.40,0.50]$} & {$[0.32,0.38]$} & {$[0.08,0.12]$} & {$[0.05,0.08]$} & {$[0.05,0.08]$} \\
\hline & $\begin{array}{c}\text { Initial } \\
\text { Requirements } \\
\text { Clear Degree } \\
\end{array}$ & {$[0.15,0.20]$} & {$[0.30,0.35]$} & {$[0.38,0.43]$} & {$[0.05,0.10]$} & {$[0.01,0.05]$} \\
\hline & $\begin{array}{c}\text { Providers' } \\
\text { Serving Ability } \\
\end{array}$ & {$[0.08,0.13]$} & {$[0.24,0.30]$} & {$[0.35,0.40]$} & {$[0.20,0.25]$} & {$[0.05,0.10]$} \\
\hline \multirow{4}{*}{$\begin{array}{l}\text { Implementati } \\
\text { on Risk }\end{array}$} & Time Risk & {$[0.20,0.25]$} & {$[0.25,0.30]$} & {$[0.30,0.35]$} & {$[0.15,0.20]$} & {$[0.01,0.05]$} \\
\hline & $\begin{array}{c}\text { Excessive } \\
\text { Expectation in All } \\
\text { Departments }\end{array}$ & {$[0.30,0.35]$} & {$[0.35,0.40]$} & {$[0.13,0,18]$} & {$[0.06,0.12]$} & {$[0.05,0.10]$} \\
\hline & $\begin{array}{c}\text { BI } \\
\text { Involvement } \\
\text { Range } \\
\end{array}$ & {$[0.44,0.50]$} & {$[0.20,0.28]$} & {$[0.15,0.20]$} & {$[0.06,0.12]$} & {$[0.05,0.10]$} \\
\hline & $\begin{array}{l}\text { Implementatio } \\
\text { n Quality }\end{array}$ & {$[0.06,0.13]$} & {$[0.15,0.20]$} & {$[0.20,0.25]$} & {$[0.40,0.45]$} & {$[0.05,0.10]$} \\
\hline
\end{tabular}

For $0.33+0.325+0.245+0.2+0.165=1.265>1$, so it is required to carry out normalization process, to obtain $=(0.3,0.257,0.194,0.158,0.131)$. According to the maximum membership degree principle, company A's implementing BI project risk level is the highest, so company A shall adopt scientific manners during BI project implementation to reduce risks. Using fuzzy distribution principle, it is indicated from the above calculation results that among company A's BI project implementation risk factors, management risk level is the highest, then technology risk and implementation risk, while external risk is relatively low.
Carry out evaluation using disturbing fuzzy comprehensive model, and carry out comprehensive consideration on various risk factors during project implementation, while carry out scientific determination on evaluating indexes via hierarchy analysis and consider human factor in evaluation, meanwhile, entitle different evaluation weights to evaluating team according to evaluating factors, to achieve a complete, objective, justice and scientific risk identification on BI project, and to provide scientific decision-making evidence for successfully implementation of company A's BI project[9]. 


\section{MEASURES TO REDUCE COMPANY A'S BI PROJECT RISKS}

According to company A's empirical analysis, among factors impacting BI project risks, dominant ones mainly focus on aspects such as management, technology and implementation, and the following three points are put forward as suggestions to reduce company A's BI project risks[10][11].

(1) Implement the head project, and carry out an overall plan. Company A shall set up a BI project leadership team focusing on high-level leadership, and plan a BI implementation model, combining the enterprise's existing inner management structure, operating management thought and business process etc.

(2) Improve informational infrastructure construction, and enhance data quality management. Company A shall carry out cleaning on existing metadata, to eliminate defects such as lack of specification, logic insufficiency and weak expandability in current data standard. While grasping the chance that no unified industrial standards have formed at present, borrow user metadata standard from advanced BI systems in retail industry and communication industry etc., and carry out unified planning and arrangement combining company A's detailed situation.

(3) Overall planning, and distributed implementation. Select the most important business of company A as the subject for analysis, and use a report form familiar to users as breakthrough point, to make users establish sensitive recognition and understanding on business intelligence at initial stage of project implementation. On this basis, guide users to further utilize various analytic tools, and make them experience advantages brought by business intelligence. After the project obtains success at a certain point, it will be easier to be promoted to a wider extent. For at this moment, this new system has been accepted by users, and more requirements will generate during usage, promoting system to develop both in scope and in depth. This is an uninterrupted cyclic process, which promotes the system to rise in a spiral manner, so as to guarantee final successful application of business intelligence system.

This dissertation is funded by Scientific Research Project of the Education Department of Zhejiang Province (Y201430451); Public Service Technology Application Research Project of Science and Technology Project of Zhejiang Province (2013C31097); Doctorial Innovation Fund of Shanghai University of Finance and Economics (CXJJ-2014-434) ; Huzhou City Natural Fund Project (2014YZ10).

\section{BIBLIOGRAPHY}

[1] Zhao Weidong. Business Intelligence. Tsinghua University Press, 2009.

[2] Chen Lei, Dong Bidan, Zhang Feng. Overview of Operational Business Intelligence Overview. Computer Engineer and Design, 2010, (7). 37-42.

[3] Liu Guangfu, Chen Xiaoli. Project Risk Assessment Based on Delphi Method and Analytic Hierarchy Process. Project Management Technology, 2008(1): 23-26.

[4] Luo Zhengqing, Yang Shanlin. Comparison on Several Scales in Analytic Hierarchy Process. System Engineering Theory and Practice, 2004(11): 52-59.

[5] W.F. Cody, J.T. Kreulen, V. Krishna, W.S. Spangler. The Integration of Business Intelligence and Knowledge Management. IBM Systems Journal,2002,41(4):697714.

[6] Li Qun. Disturbing Problem and Operator Research of Membership Function. Dalian University Journal. 2001, (4): 371-376.

[7] Li Shiyong. Engineering Fuzzy Mathematics with Applications. Harbin Institute of Technology Press, 2004.

[8] Xie Jijian, Liu Chengping. Fuzzy Mathematics Methods and Its Application. 2nd edition. Huazhong University of Science and Technology Press, 2000:78-84.

[9] Han Chengshuang, Wu Haifeng. Risk Analysis and Implementation Strategies. Journal of Hebei University of Technology, 2007(4): 11-14.

[10] Chang Hong, Gao Yunli. Application of Risky Matrix Method in Engineering Project Risk Management. Journal of Industrial Technological Economics, 2007(11): 134137.

[11] Shen Jianming. Project Risk Management. Beijing: China Machine Press, 2007. 